\title{
Precise evaluation of Building Performance through the availability of dynamic building data and a Building Information Model (BIM)
}

\section{Brian Cahill}

Informatics Research Unit for Sustainable Engineering (IRUSE), School of Engineering, UCC

\section{Introduction}

All Buildings need to provide and maintain consistent user comfort while at the same time be efficient in their use of energy with a focus on reducing operation costs and $\mathrm{CO} 2$ footprint. It is a natural business need to have our building stock operating efficiently. A building that operates efficiently is one where most characteristics of the building can be monitored and evaluated while responding with essential actuation. Facility Management companies enter into service level agreements with building owners where they must provide a quality of service to all occupants and building stakeholders. It is currently impossible to precisely document how a specific zone in a building is performing, or will perform, in relation to user comfort, energy usage and cost (maintenance, running costs) if no sub-metering or accurate systemic details are present for that zone. This $\mathrm{PhD}$ research proposes a solution to this problem by integrating a Dynamic Building Information Model with current Building Performance Data Monitoring resources.

\section{What is BIM?}

A Building Information Model (BIM) is a useful tool in a facility management company's ability to store data concerning a specific building. When one reads the word model immediate images of building drawings and 3-dimensional miniature structures made from card-board come to mind. Figure 1 illustrates BIM as a software facility that allows users to store all digital aspects of a building in a number of supported formats, analyse building geometry, plan and manage projects, further amend drawings, visualise buildings and use data for manufacturing building components. BIM has proved over time to be a valuable asset in contributing to the management of relevant building data. The function, general usage and opinion of BIM in industry are reminiscent of a repository for static digital building data Figure 1. 


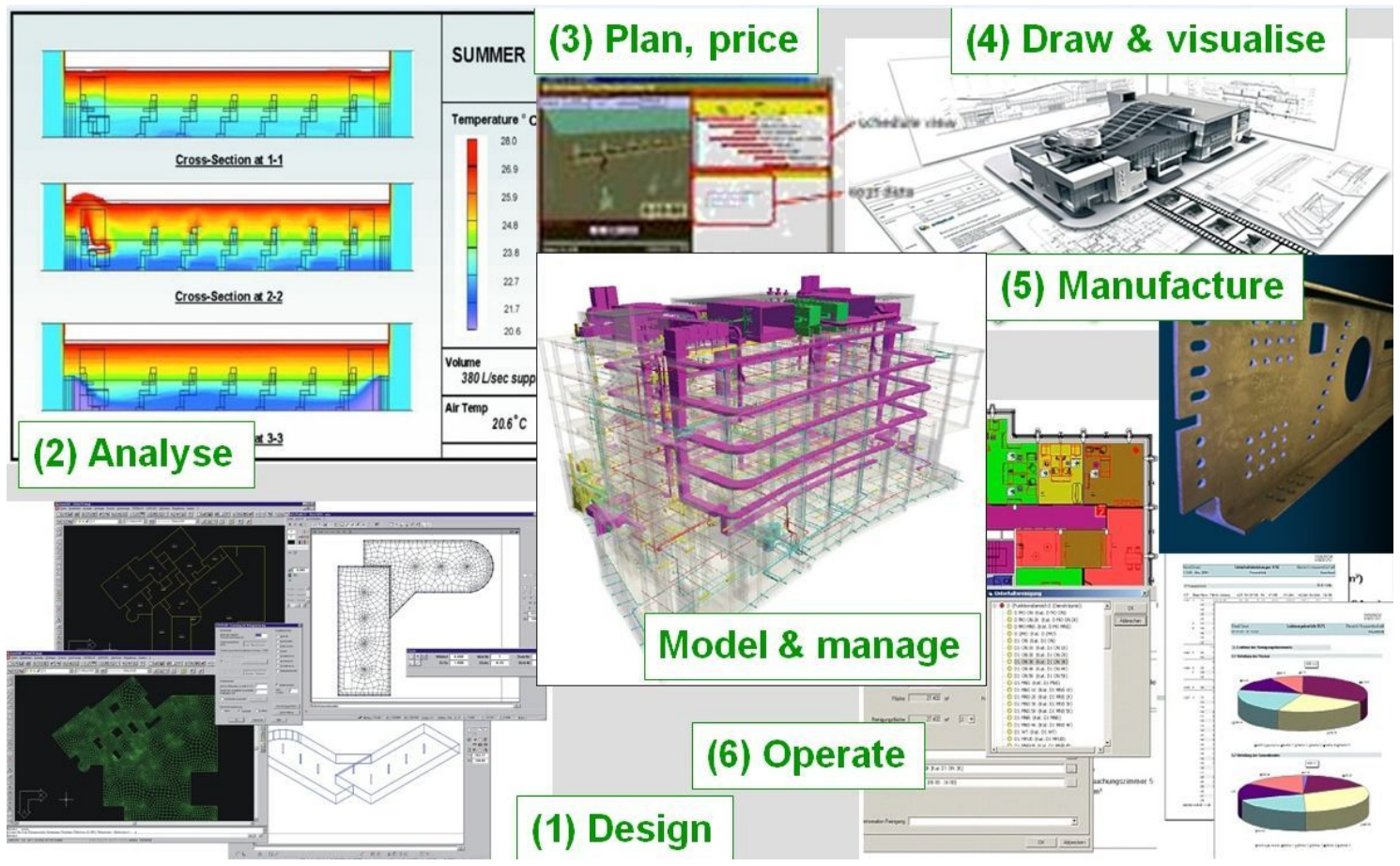

Figure 1: Building Information Model (BIM)

\section{BIM and the Building Lifecycle}

It is also worth mentioning that a BIM performs a different role depending on what stage the building is at in its lifetime. A BIM has a role to play at the concept and design stage. Efficient use of BIM at the design stage has seen a huge reduction in building costs. During construction, a BIM is useful for progress monitoring, managing costs and project plans. When the building becomes occupied with tenants, a BIM is useful for tracking energy usage, occupant and maintenance history. Finally, a building will at some stage need to be demolished and recycled. A BIM has a role to play here too in preserving all the history concerning the building's structure during its lifetime while also recording where building material were disposed of and recycled. It cannot be overstated enough how important the BIM is with reference to building data during a building's lifecycle.

\section{Making BIM Dynamic}

While BIM offers the potential of hosting all data associated with the building lifecycle, there is evidence to suggest that some phases of building lifecycle data are represented in a much more diluted fashion in a typical BIM. To date, a BIM relies heavily on manual updates from engineering staff. BIM's effectiveness becomes stronger with less manual interaction. Depending on human interaction to amend BIM based material can result in missing and duplicate data. Slow interaction with BIM based building models may 
possibly embed inaccurate and obsolete information.

A BIM can become more efficient in the way it stores and retrieves data while also giving the geometrical data more meaning. This research examines how a dynamic BIM can be supported by integrating wired and wireless sensed building data sources, such as a Data Warehouse, and, as such, provides a solid platform to perform precise evaluations of relevant building performance, at any stage of the building's lifecycle. This research will primarily focus on the operation phase of a building lifecycle where occupant energy usage, occupant comfort and building zone performance take priority.

\section{Proving the concept of Dynamic BIM}

As a proof of concept, this research focuses on using a BIM tool supporting a web browser based client with the following features:

Industry Foundation Class building drawing file formats

Industry Foundation Class versioning, Geographic Information System

Building Drawing Data Filtering

Web-browser Interface

In addition, current "Living Laboratories" have provided this research with more that 100 million datasets containing humidity, $\mathrm{CO} 2$, radiant temperature, weather data, occupancy data, HVAC performance data, and overall building performance data. Current "Living Laboratories" include the Environmental Research Institute (ERI), UCC and the HSG zander Hotel and Training Centre, Neu Isenburg, Frankfurt, Germany. Figure 2 illustrates a current supported web-based application that displays building performance data from the ERI. The user simply clicks a relevant icon in the building floor schematic and a resultant two weeks period of specific building data is displayed. An enhancement of this application would be to integrate a similar tool that references the BIM and displays specific detail concerning building zones such as window type, door type, occupant levels, and history of energy usage.

\section{Proposed Software Architecture}

Current academic literature on the subject of BIM is preoccupied with how BIMs can be supported and how they can reproduce and exchange geometric data between numerous Computer Aided Design (CAD) drawing tools. This research pulls the topic of BIM in a different direction. Referring to figure 3, a BIM contains predominantly descriptive and static data. A Data Warehouse, on the other hand, supports data which is largely dynamic. 
Zone: ERI Lower Ground Floor
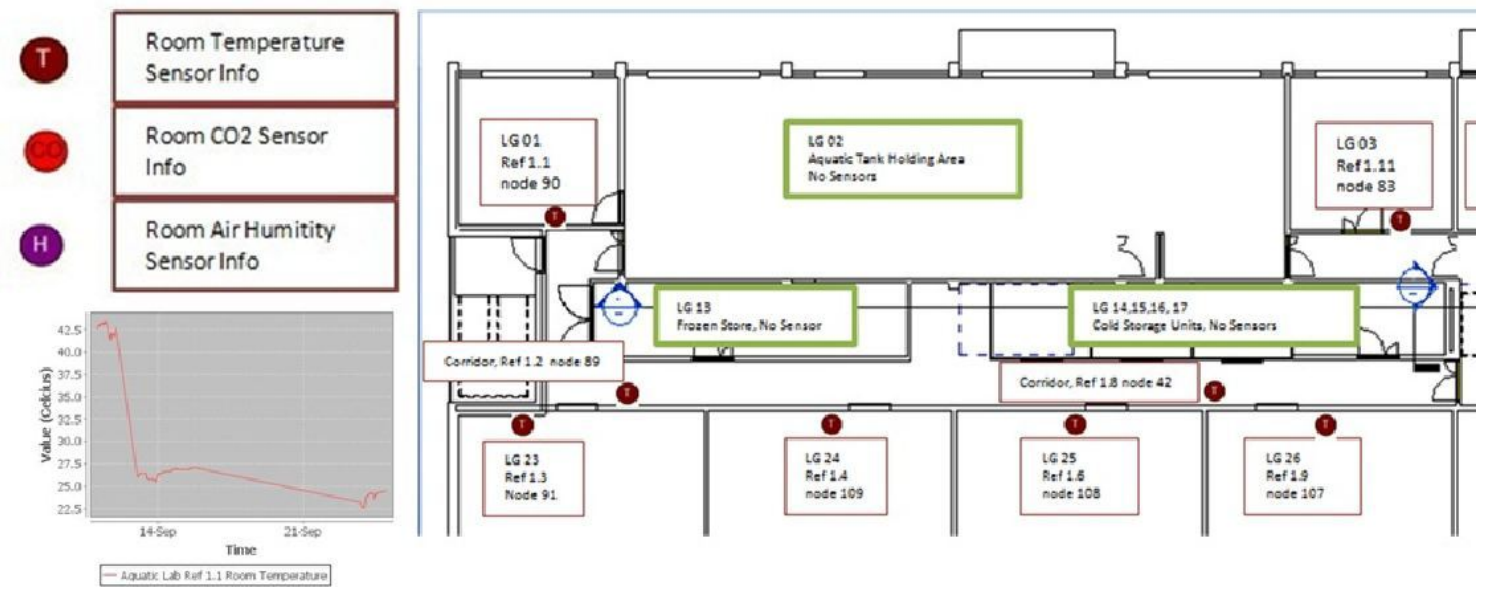

Figure 2: Building Performance Monitoring of the ERI

Data is sourced from wired and wireless meters deployed in buildings. In addition the architecture illustrated in figure 3 also supports data sources from RFID equipment used to detect occupants and track equipment. The sensor and actuation network involves, as mentioned, wired and wireless sensors coupled with actuation devices such as actuating windows, blinds, and under floor heating valves. The top layer of this architecture supports simulation activities where simulated output can be stored at the BIM. Maintenance tools incorporate how maintenance tasks are detected, scheduled, resolved and resourced. Monitoring Tools focus on retrieving data from both the BIM and the Data Warehouse where user interfaces/dash boards are designed to support stakeholder information requirements. The Intelligent Control supports the analysis of incoming sensed data.

\section{Research Outcome}

This research will focus on merging the abilities of the BIM and the Data Warehouse to produce a total Dynamic BIM solution where static data from the BIM will be enriched with dynamic data from the Data Warehouse such as room temperature, room occupancy levels, CO2 levels and much more. We are talking about capturing dynamic building performance data at a particular point in time and storing this data in a version of a BIM server based building model.

In addition to the above task, this research will examine how to further enrich dynamic BIM data by applying simulated data, and data produced through a Data Warehouse's data analysis techniques. The real goal in this research is to prove how such a dynamic BIM can precisely evaluate building performance and facilitate prognosis of building inspection, 


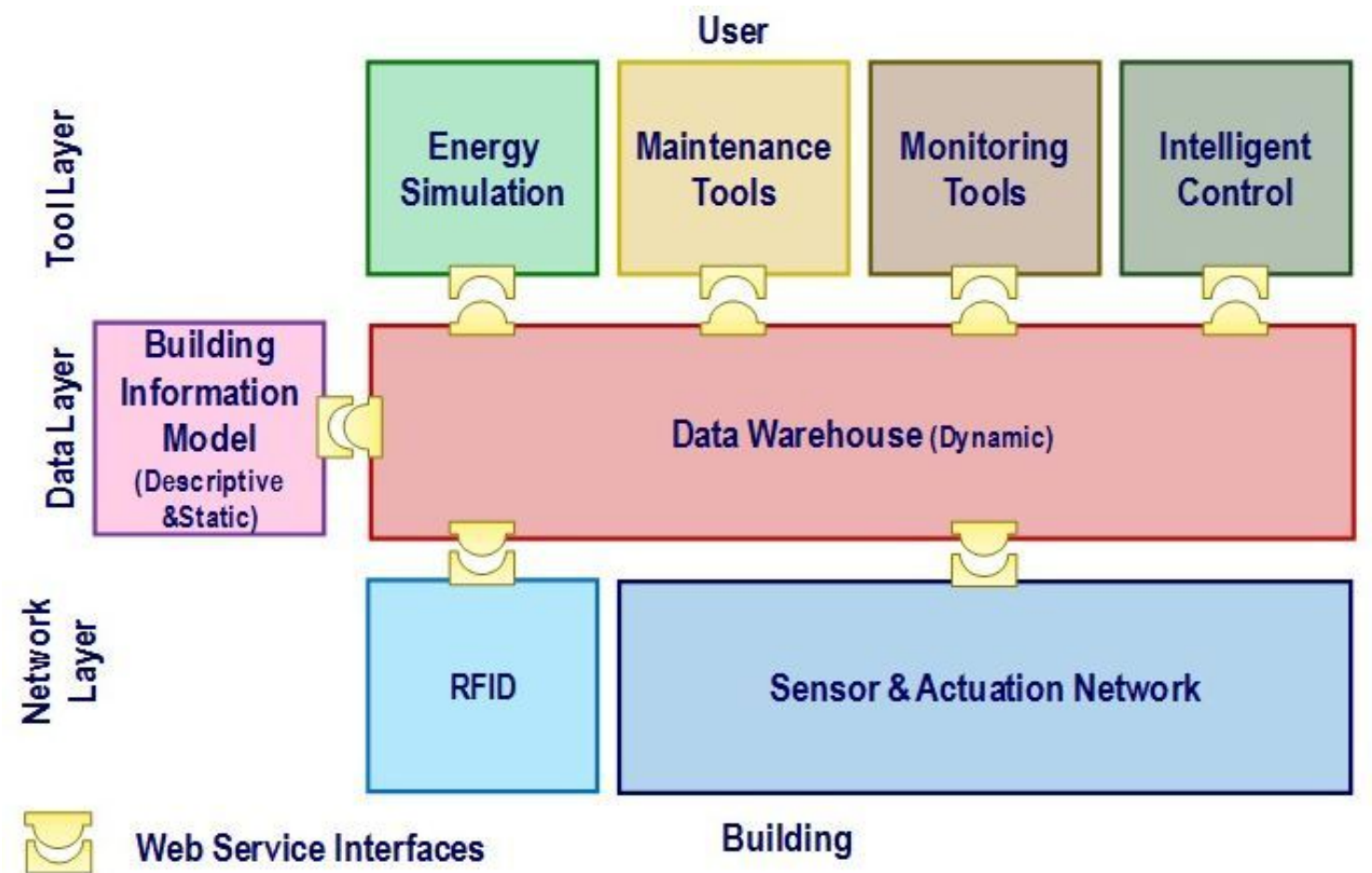

Figure 3: Dynamic Building Information Model Architecture

maintenance, actuation and renovation.

The author would like to acknowledge the work of the Science Foundation Ireland funded Scientific Research Cluster IT for Optimised Building Operation (ITOBO) and the Informatics Research Unit for Sustainable Engineering (IRUSE) based in the Civil and Environmental Engineering Department, School of Engineering, University College Cork. Brian Cahill is a PhD student in the School of Engineering, under the supervision of Professor. Karsten Menzel, Chair IT in Architecture, Engineering and Construction, Director of the Informatics Research Unit for Sustainable Engineering (IRUSE), UCC. 